\title{
Hydroxyapatite Formation on the Antase Phasetitanium Dioxide Nanoparticles
}

\author{
C. K. Senthilkumaran ${ }^{1 *}$ and S. Sugapriya ${ }^{2}$ \\ sks.apsc@psgtech.ac.in, sugapriya0314@gmail.com
}

${ }^{1}$ Department ofApplied Science, PSG College of Technology, Coimbatore, India.,

${ }^{2}$ Department of Chemistry, Coimbatore Institute of Technology, Coimbatore, India.

\begin{abstract}
The The objective of in-vitro study was aimed to synthesize and characterize the nanoparticles of Titanium dioxide $\left(\mathrm{TiO}_{2}\right)$ and Hydroxiapatite (Hap). The anatase phase Titanium dioxide nanoparticles were synthesized using chemical precipitation method. This study demonstrates the efficient growth of hyroxyapatite over the surface of $\mathrm{TiO}_{2}$ nanoparticles under the medium of in-vitro studies of $1 \mathrm{SBF}$ and 1.5 SBF separately at body temperature $36.5^{\circ} \mathrm{C}$ using the BOD incubator. The growth of HAp over the surface of $\mathrm{TiO}_{2}$ nanoparticles are confirmed by structural studies, surface morphology, chemical composition and vibrational stretching. While comparing the results of anatase phase of $\mathrm{TiO}_{2}$ nanoparticles, anatase phase of $\mathrm{TiO}_{2}$ nanoparticles in 1.5 SBF had higher growth of HAp than anatase phase $\mathrm{TiO}_{2}$ nanoparticles in $1 \mathrm{SBF}$.
\end{abstract}

Keywords: $\mathrm{TiO}_{2}$ nanoparticles, Anatase phase, Hydroxyapatite, $1 \mathrm{SBF}, 1.5 \mathrm{SBF}$.

\section{Introduction}

Due to the high biotolerance, adequate mechanical properties, nontoxicalsoity and corrosion resistance of Titanium dioxide and alloys of $\mathrm{TiO}_{2}$ have been broadly used in orthopedic and dental fields as biomaterials for permanent implants materials $(1,2)$. Due to the mechanical property, titanium shows a mechanically stable interface towards bone. The capacity of the bone bonding and bioactivity of implant surfaces has been developed by the $\mathrm{TiO}_{2}(3,4)$. The major inorganic component of bones, teeth and hard tissue in mammals [Hydroxyapatite (HAp) $\left.\left(\mathrm{Ca}_{10}\left(\mathrm{PO}_{4}\right)_{6}(\mathrm{OH})_{2}\right)\right](5)$ and also it is the most widely used bioceramics for orthopaedic and dental applications, which gives excellent bio-activity, biocompatibility and strong bonding natural bones.

In order to improve the capacity of bone-bonding ability, titanium and its alloys are often used to develop HAp. Implanting $\mathrm{TiO}_{2}-\mathrm{HAp}$ over the surface of the bone tissue will form a chemical bond with the bone to motivate the promotion of bone growth. In recent decades, a number of researchers have concentrated on the interesting field of biological application. The arrangements of a bioactive surface layer directly on $\mathrm{TiO}_{2}$ substrate would prompt the apatite evolution in the living environment or simulated body fluid (SBF). In this study, the anatase phases of $\mathrm{TiO}_{2}$ nanoparticles were prepared as a pellet form to investigate the in-vitro apatite arrangements in order to assess the calcium and phosphorous percentage in SBF, which is required to make bone-like apatite. 


\section{Methods And Materials}

In the present work, the prepared [6] anatase phase at an annealing temperature $450^{\circ} \mathrm{C}$ of $\mathrm{TiO}_{2}$ nanoparticles are separately prepared to pellets by using hydraulic pressure pelletizer. One gram of $\mathrm{TiO}_{2}$ powder (i.e., anatase phase) was pressed uniaxially to acquire disk-shaped pellet of $15 \mathrm{~mm}$ dia and $0.5 \mathrm{~mm}$ thickness preceding to an isostatic pressing at $100 \mathrm{MPa}$.

$\mathrm{SBF}$ (1 SBF and 1.5 SBF) aqueous solution was synthesised for the formation of apatite in one litre of solution by adding the reagents proposed by Kokubo and his colleagues [7]. A solution with ion concentrations 1 and 1.5 times of SBF (1.5SBF) can be synthesised, in order to stabilize the apatite formation.

The prepared anatase phases $-\mathrm{TiO}_{2}$ pellets were immersed in $50 \mathrm{~mL}$ of $1 \mathrm{SBF}$ and also 1.5 SBF separately in the polyethylene container under body temperature $36.5^{\circ} \mathrm{C}$ using the BOD incubator. For every 24 hours, the used solution was drained out and filled with another fresh solution. Exactly, after the $5^{\text {th }}$ day of immersing, the pellets were removed from the solution, washed with distilled water and dried below $50{ }^{\circ} \mathrm{C}$ for one hour to remove the moisture from the pellets. After that they were characterized.

The above procedure was repeated for the same characterized pellets to proceed up to $10^{\text {th }}$ day of immersing and $15^{\text {th }}$ day of immersing. Exactly, after the $10^{\text {th }}$ and $15^{\text {th }}$ day of immersing, the pellets were removed from the solution, washed with distilled water and dried below $50{ }^{\circ} \mathrm{C}$ for one hour to remove the moisture from the pellets. After that they were characterized.

In this study, XRD(X-ray diffraction) were observed using PANalytical X-ray diffractometer. The surface morphologies and energy dispersive X-ray energy spectroscope of synthesized nanoparticles was analysed by Field emission scanning electron microscope (FESEM) with EDX in CARLZEISS SIGMA version. Fourier Transform Infrared spectroscopy (FTIR) analyses were recorded by using SHIMKDZU IRAffinity - 1 instrument to confirm the compound and nanoparticles formation.

\section{Result And Discussion}

\subsection{Structural Studies}

The XRDformation of annealed at $450^{\circ} \mathrm{C}$ of $\mathrm{TiO}_{2}$ samples after immersing into the $1 \mathrm{SBF}$ and 1.5 SBF solution under body temperature shown in Figures 1.1 and 1.2 (a, b \& c) are the diffraction peaks corresponding tothetetragonal BCC of the anatase phases of $\mathrm{TiO}_{2}(101)$, (004), (200), (105), (204), (220) and (107) crystal planes. The lattice constants were found to be $\mathrm{a}=3.745 \AA$ and $\mathrm{c}=9.510 \AA$, and in good agreement with standard (JCPDS) card No. 894921. Along with this diffraction peaks there was presence of other diffraction peaks (211), (202) and (140) crystal planes of hexagonal primitive of the Calcium Hydroxide Phosphate $\left(\mathrm{Ca}_{10}\left(\mathrm{PO}_{4}\right)_{6} \mathrm{OH}_{2}-\mathrm{Hydroxyapatite}\right)$ represents in graph as HAp.The lattice constants have been found to be $\mathrm{a}=9.248 \AA$ And $\mathrm{c}=6.593 \AA$ which was with the standard (JCPDS) card No. 74$0565(8)$.

From the XRD, the phase of the $\mathrm{TiO}_{2}$ nanoparticles is mainly of nano-crystalline anatase type tetragonal symmetry with the presence of hexagonal symmetry of hydroxyapatite. The intensities of the peaks describes the hydroxyapatite were increased because the immersing period was increased by days.

The observation indicates that the growth of HAp increases with increase inthe immersing period of days from 5 to 15 days in both the concentration $1 \mathrm{SBF}$ and $1.5 \mathrm{SBF}$. The growth of 
HAp improvement is proportional to the increase in the intensity of the diffraction peak. The growth of the HAp in the concentration of $1.5 \mathrm{SBF}$ solutions was higher than the concentration of $1 \mathrm{SBF}$ solution.
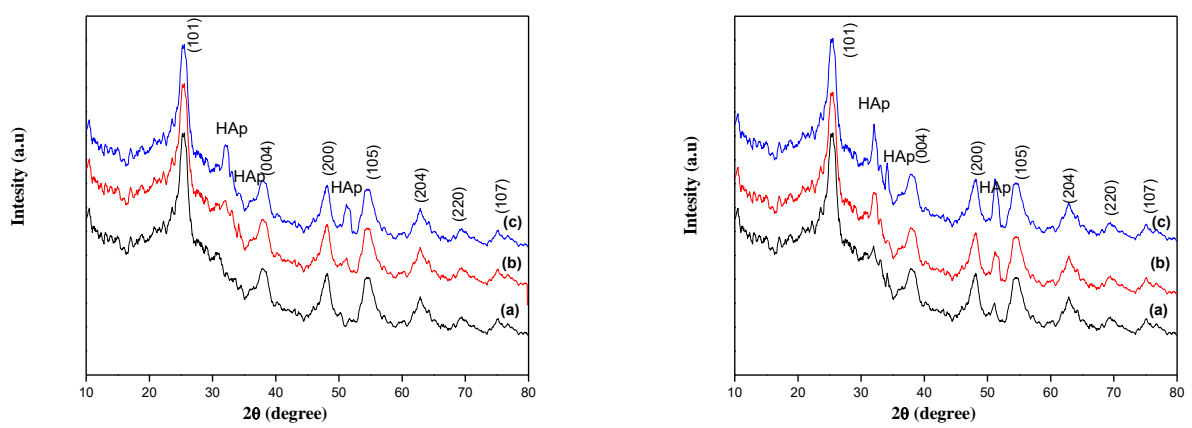

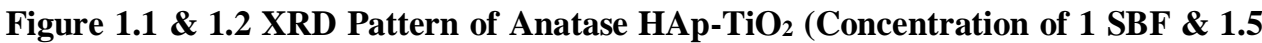
SBF immersed after(a) $5^{\text {th }}$ day, (b) $10^{\text {th }}$ day and (c) $15^{\text {th }}$ day in SBF)

By comparing the XRD patterns of HAp on anatase phase- $\mathrm{TiO}_{2}$ nanoparticles in $1 \mathrm{SBF}$ and 1.5 SBF. The anatase phase $-\mathrm{TiO}_{2}$ nanoparticles in 1.5 SBF has more growth of HAp (calcium and phosphate) than the anatase phase $-\mathrm{TiO}_{2}$ nanoparticles in $1 \mathrm{SBF}$.

\section{Surface Morphological Studies}

The formations of HAp over $\mathrm{TiO}_{2}$ nanoparticles can be seen in FESEM Figures 2(a f). The sample shows the agglomerated grains with random shapes and the distributions of grains were regular spherical shape through all the regions with the formation of calcium and phosphate (HAp) over the sample. Figure 2(a-c) FESEM images of anatase phase of HAp$\mathrm{TiO}_{2}$ nanoparticles in the concentration of $1 \mathrm{SBF}$ solution. The yellow colour circles in the image shows the formation of calcium and phosphate (HAp). The observation of Figure 2(a-c) indicates the increase in the formation of calcium and phosphatespersentage with increasingthe immersing period from 5 to 15 days in the concentration 1 SBF solution. Similarly Figure 2(d-f) depicts the FESEM images in the concentration of 1.5 SBF solution. The yellow circles of this image show that, there was increase in the formation of calcium and phosphate ratio with increase inthe soaking period from 5 to 15 days in the concentration 1.5 SBF solutions.

Figure 2.1 indicates the growth of HAp increases with increase in the soaking period from 5 to 15 days in both the concentration of $1 \mathrm{SBF}$ and 1.5 SBF solutions. The growth of HAp improvement is responsible for the increase in the yellow marked circles. The growth of the HAp in the concentration of $1.5 \mathrm{SBF}$ solutions was higher than the concentration of $1 \mathrm{SBF}$ solutions in anatase phase of $\mathrm{TiO}_{2}$ nanoparticles.

The FESEM images reveal the crystallites were nanoscale in size. Therefore, the growth of HAp was also in nanoscale range over the $\mathrm{TiO}_{2}$ nanoparticles on the anatase phases under the concentration of $1 \mathrm{SBF}$ and 1.5 SBF solutions. By comparing the FESEM images, the anatase phase- $\mathrm{TiO}_{2}$ nanoparticles in $1.5 \mathrm{SBF}$ have more growth of HAp (calcium and 
phosphate) than the anatase phase- $\mathrm{TiO}_{2}$ nanoparticles in $1 \mathrm{SBF}$.The $\mathrm{HAp}-\mathrm{TiO}_{2}$ is due to the increase in concentration of SBF with maximum soaking period as similarly shown in XRD results.

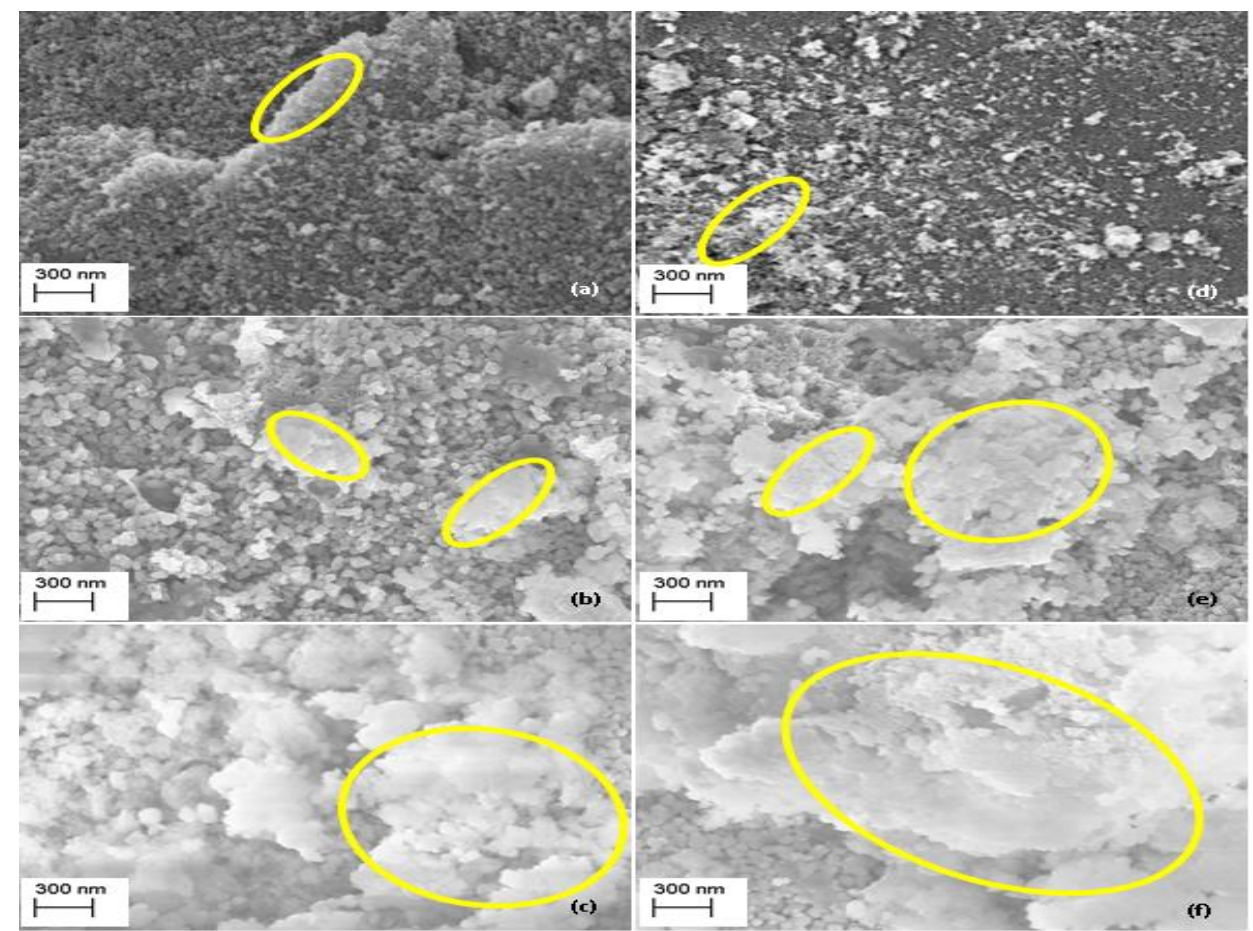

Figure 2FESEM images of AnataseHAp-TiO 2 nanoparticles (immersed after in $1 \mathrm{SBF}$ (a) $5^{\text {th }}$ day, (b) $10^{\text {th }}$ day and (c) $15^{\text {th }}$ day \& immersedafter in $1.5 \mathrm{SBF}$ (d) $5^{\text {th }}$ day, (e) $10^{\text {th }}$ day and (f) $15^{\text {th }}$ day)

\section{Compositional Analysis}

Energy dispersive X-ray energy spectroscopeanalysis was used to determine the composition of the $\mathrm{TiO}_{2}$ nanoparticles with the presence of calcium and phosphate to justify the growth of HAp. Figures 3.1 to $3.2(\mathrm{a}-\mathrm{c})$ show the elements of $\mathrm{Ti}, \mathrm{O}, \mathrm{Ca}$ and $\mathrm{P}$ presents. Thus, the spectroscopeanalysis indicates that the obtained $\mathrm{HAp}-\mathrm{TiO}_{2}$ nanoparticles were pure representing the growth of artificial bone. Figure 3.1 and 3.2 depicts the chemical composition of Ti, O, Ca and $\mathrm{P}$ with anatase phase in the concentration of $1 \mathrm{SBF}$ and $1.5 \mathrm{SBF}$ solutions. Mainly there was increase in the composition of $\mathrm{Ca}$ and $\mathrm{P}$ with increase in the soaking period and also in concentration.

When comparing the anatase phases of $\mathrm{HAp}-\mathrm{TiO}_{2}$ in both the concentration of 1 and 1.5 SBF solutions, the anatase phase of $\mathrm{HAp}-\mathrm{TiO}_{2}$ nanoparticles in $1.5 \mathrm{SBF}$ has more growth of calcium and phosphate. $\mathrm{HAp}-\mathrm{TiO}_{2}$ concentration is raised due to the increase in concentration of SBF with maximum immersing period as similarly shown in XRD and FESEM results. 


\section{FTIR Spectral Analysis}

Fourier transform infrared spectra were observed using a SHIMKDZU IRAffinity - 1 spectrometer(9). Figures $4.1 \& 4.2$ shows the spectrum of anatse phase $\mathrm{HAp}^{-\mathrm{TiO}_{2} \text { nanoparticles }}$ of $1 \mathrm{SBF}$ and 1.5 SBF solutions under different immersing period of days.

Figures 4.1 show the approximately similar bands occurred corresponding to the growth of $\mathrm{HAp}-\mathrm{TiO}_{2}$ nanoparticles. The peak at $3500 \mathrm{~cm}^{-1}$, were stretching vibration of $\mathrm{OH}$ groups and the symmetric and antisymmetric $\mathrm{OH}$ peaks of molecular $\mathrm{H}_{2} \mathrm{O}$ with in $\mathrm{TiO}_{2}$ nanoparticles.

The bending vibration to the molecular $\mathrm{H}_{2} \mathrm{O}$ bending band is at $1600 \mathrm{~cm}^{-1}$. The $\mathrm{TiO}_{2}-\mathrm{OH}$ bonds formed from the hydrolysis reaction. While the peakfrom 2800 to $2970 \mathrm{~cm}^{-1}$ corresponds to symmetric stretching of $\mathrm{CH}$ and $\mathrm{CH}_{2}$ bands, the in-plane skeletal vibrations of aromatic ringsaroundthe peaks from 1300 to $1500 \mathrm{~cm}^{-1}$. The modes at 450 to840 $\mathrm{cm}^{-1}$ indicate the stretching vibrations of anatase phase $\mathrm{TiO}_{2}$ nanoparticles along with the $\mathrm{PO}_{4}{ }^{3-}$ and $\mathrm{Ca}^{2+}$.
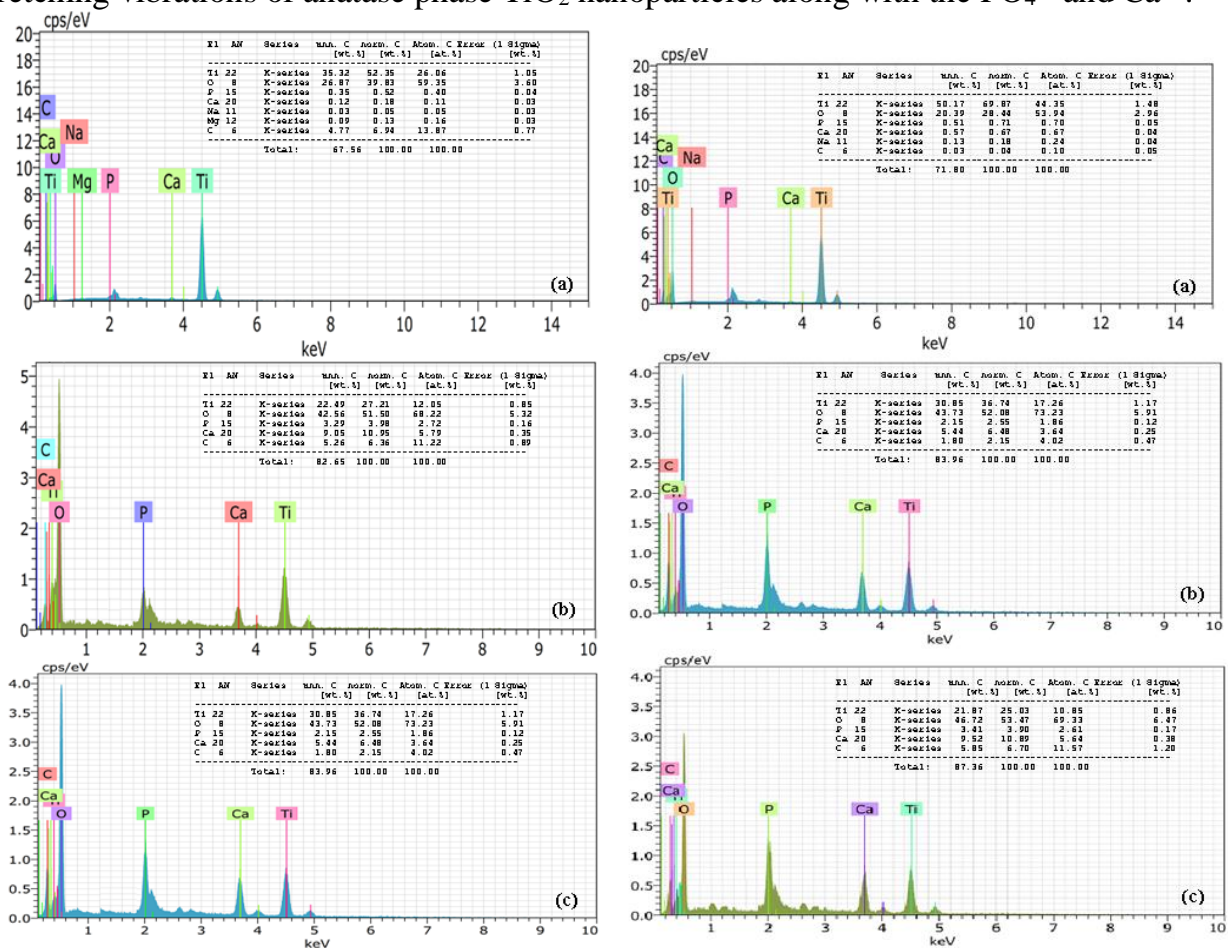

Figure 3.1 \& 3.2EDAX pattern of AnataseHAp-TiO 2 nanoparticles (immersed after in $1 \mathrm{SBF} \& 1.5 \mathrm{SBF}(\mathrm{a}) 5^{\text {th }}$ day, (b) $10^{\text {th }}$ day and (c) $15^{\text {th }}$ day) 

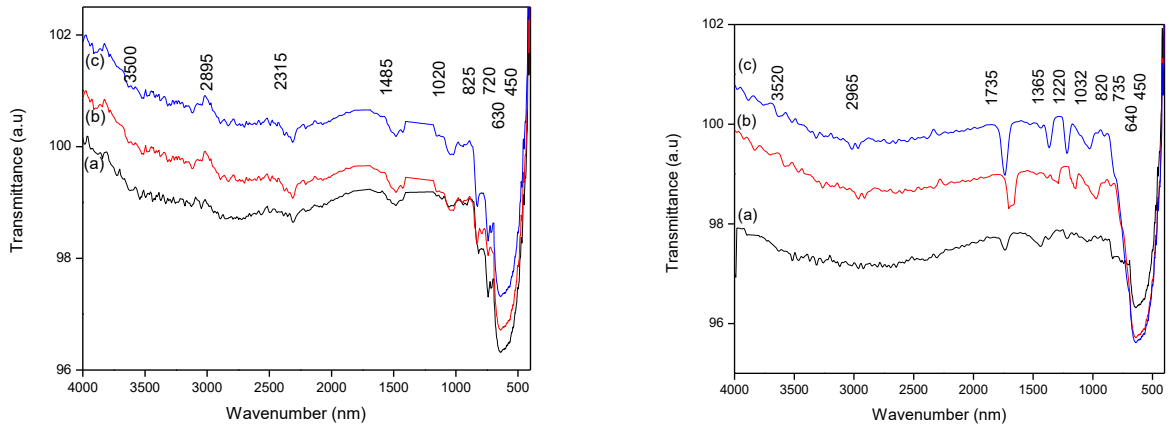

Figure 4.1 \&4.2FRIR Pattern of Anatase $\mathrm{HAp}^{-\mathrm{TiO}_{2}}$ (Concentration of $1 \mathrm{SBF} \& 1.5$ SBF immersed after(a) $5^{\text {th }}$ day, (b) $10^{\text {th }}$ day and (c) $15^{\text {th }}$ day in SBF)

In Figures 4.1 to 4.2 , the FTIR peaks of anatase phase of $\mathrm{HAp}-\mathrm{TiO}_{2}$ nanoparticles in the concentration of $1 \mathrm{SBF}$ and $1.5 \mathrm{SBF}$ are shown. The FTIR result proves the formation of HAp over $\mathrm{TiO}_{2}$ nanoparticles rises gradually while the period of soaking day increases.

\section{Growth Mechanism of HAp on TiO2 Nanoparticles}

In this study, crystal planes of hexagonal primitive of the Calcium Hydroxide Phosphate $\left(\mathrm{Ca}_{10}\left(\mathrm{PO}_{4}\right)_{6} \mathrm{OH}_{2}-\right.$ Hydroxyapatite $)$ represents as $\mathrm{HAp}-\mathrm{TiO}_{2}$ nanoparticles under the SBF solution at a human body temperature. The prepared anatase phase of $\mathrm{TiO}_{2}$ nanoparticles are taken for this study of bonelike apatite. The SBF (1 SBF and 1.5 1.5 SBF) aqueous solution with the ion concentration were prepared separately by adding the chemicals like $\mathrm{NaCl}$, $\mathrm{NaHCO}_{3}, \mathrm{KCl}, \mathrm{K}_{2} \mathrm{HPO}_{4} .3 \mathrm{H}_{2} \mathrm{O}, \mathrm{MgCl}_{2} .6 \mathrm{H}_{2} \mathrm{O}, \mathrm{HCl}, \mathrm{CaCl}_{2}, \mathrm{Na}_{2} \mathrm{SO}_{4}$ and $\left(\mathrm{CH}_{2} \mathrm{OH}\right)_{3} \mathrm{CNH}_{2}$ in distilled water. This reagent is dissolved into an ion exchanged gives the concentration of distilled water ions as $\mathrm{Na}^{+}, \mathrm{K}^{+}, \mathrm{Mg}^{2+}, \mathrm{Ca}^{2+}, \mathrm{Cl}^{-}, \mathrm{HCO}_{3}^{-}, \mathrm{HPO}_{4}^{2-}$ and $\mathrm{SO}_{4}{ }^{2-}$ are clearly shown under the EDAX and FTIR analysis. The pellet of $\mathrm{TiO}_{2}$ nanoparicles were immersed in $50 \mathrm{~mL}$ of $1 \mathrm{SBF}$ and $1.5 \mathrm{SBF}$ in a polystyrene container at body temperature under BOD incubator which has in-built of cooler, heater, UV lamp and illumination light. Due to the presence of aqueous solution $\mathrm{TiO}_{2}$ nanoparicles tends to monitor the $\mathrm{H}_{2} \mathrm{O}$ molecules over the surface to form $\mathrm{TiO}_{2}$ group. UV illumination light was responsible to accelerate the formation of bonelike apatite. The bone-like apatiteis composed with the calcium and phosphates i.e., the Calcium $\left(\mathrm{Ca}^{2+}\right)$ and the phosphorous $\left(\mathrm{HPO}_{4}{ }^{2-}\right)$ present in the SBF solution are deposited over the Ti-OH surface of $\mathrm{TiO}_{2}$ nanoparicles as calcium $\left(\mathrm{Ca}^{2+}\right)$ and phosphates $\left(\mathrm{PO}_{4}{ }^{3-}\right)$. 


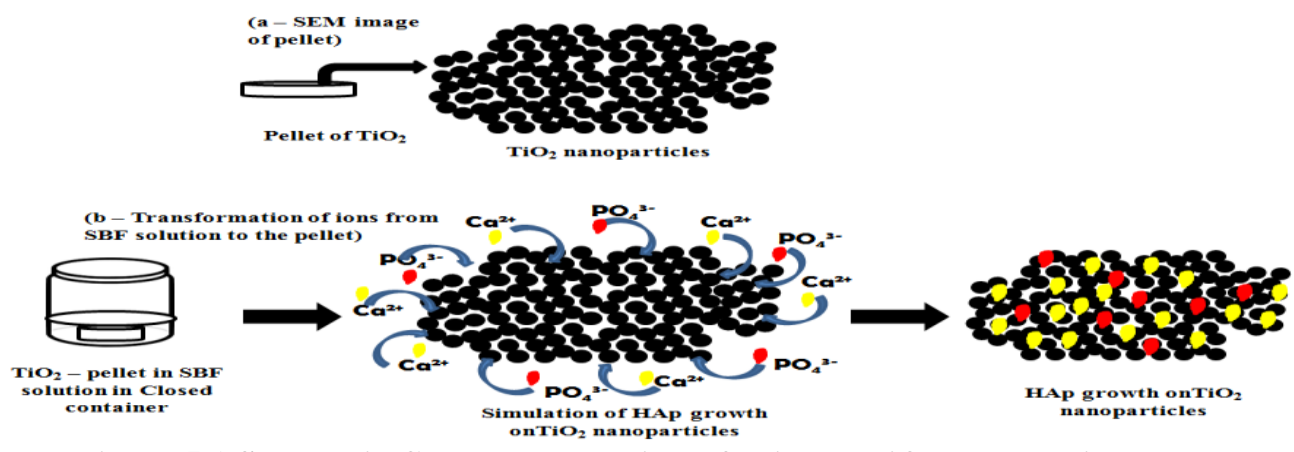

Figure 5.1 Schematic Growth Mechanism of HAp on $\mathrm{TiO}_{2}$ nanoparticles in SBF Solution

Figure 5.1 depicts the mechanism of the bone like apatite growth over the $\mathrm{TiO}_{2}$ nanoparticles. The powder form of $\mathrm{TiO}_{2}$ nanoparicles were made to pellet form. The schematic image is given in Figure 5.1(a). The particles were closely arranged in a random manner. Figure 5.1(b) is the schematic diagram that represents the formation of bone like apatite i.e., $\mathrm{Ca}^{2+}$ and $\mathrm{PO}_{4}{ }^{3-}$ simulated over the surface of $\mathrm{TiO}_{2}$ nanoparicles. Thus, the growth of HAp over the surface of $\mathrm{TiO}_{2}$ nanoparicles is finally shown.

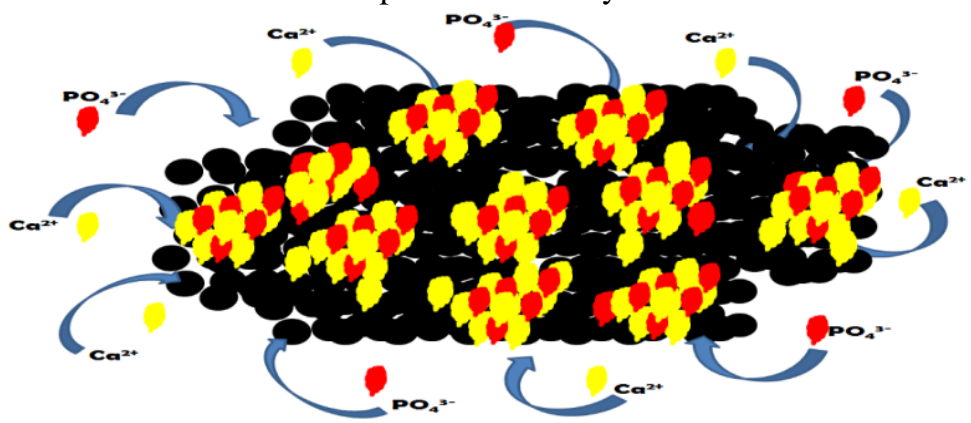

Figure 5.2 Schematic Picture of HAp Growth over $\mathrm{TiO}_{2}$ nanoparticles

The FESEM images of the HAp over the $\mathrm{TiO}_{2}$ nanoparicles were visible in Figures 5.1 and 5.2. In those figures, the HAp was seen like foam formation over the surface of $\mathrm{TiO}_{2}$ nanoparicles. Thus, a similar mechanism was seen in Figure 5.2 as schematic representation of the HAp growth over the surface of $\mathrm{TiO}_{2}$ nanoparicles.

\section{Conclusion}

The growth of HAp over the surface of $\mathrm{TiO}_{2}$ nanoparticles is confirmed by the structural studies, surface morphology, chemical composition and vibrational stretching. While comparing the results of anatase phase of $\mathrm{TiO}_{2}$ nanoparticles, anatase phase of $\mathrm{TiO}_{2}$ nanoparticles in 1.5 SBF had higher growth of $\mathrm{HAp}$ than anatase phase $\mathrm{TiO}_{2}$ nanoparticles in 1 SBF. 


\section{References}

[1] Guided bone regeneration: Materials and biological mechanismsrevisited,Elgali, I. Omar, O. Dahlin, C. Thomsen, P. 2017, Eur. J. Oral Sci., 125, 315-337.

[2] Synthesis, Characterization, and Photocatalysis of Well-Dispersible Phase-Pure Anatase TiO2 Nanoparticles, XiuzhenWei, Guangfeng Zhu, Jinfeng Fang, and Jinyuan Chen, 2013, International Journal of Photoenergy, Vol. 2013, Article ID 726872, 6 pages.

[3] Local Cellular Responses to Titanium Dioxide from Orthopedic Implants. Yao, J. J. et al. 2017, BioResearch. 6, 94-103.

[4] Electrophoretic deposition of nanocomposite ( $\mathrm{HAp}+\mathrm{TiO} 2)$ on titanium alloy for biomedical applications, L. Mohan, D. Durgalakshmi, M. Geetha, T.S.N. Sankara Narayanan, R. Asokamani, 2012, Ceramics International, Vol. 38 (2012), pp. 3435-3443.

[5] Xiong Lu, Hongping Zhang, Yanan Guo, Yingbo Wang, Xiang Ge, Yang Leng \& Fumio Watari 2011, 'Hexagonal hydroxyapatite formation on TiO2 nanotubes under urea Modulation', CrystEngComm, vol. 13, pp. 3741-3749.

[6] Effect of annealing on TiO2 Nanoparticles, Sugapriya .S, Sriram .R, Lakshmi .S, 2013, Optik: International journal for Light and Electron optics, Volume 124, Issue 21, Pages 4971-4975.

[7] Mechanism of apatite formation on $\mathrm{CaO}-\mathrm{SiO} 2-\mathrm{P} 2 \mathrm{O} 5$ glasses in a simulated body fluid, Chikara Ohtsuki, Tadashi Kokubo and Takao Yamamuro, 1992 J. Non-Crystl. Solids, 143, 84-92.

[8] Bioactivation of titanium surfaces using coatings of $\mathrm{TiO} 2$ nanotubes rapidly pre-loaded with synthetic hydroxyapatite, Kodama, A, Bauer, S, Komatsu, A, Asoh, H, Ono, S \& Schmuki, P 2009, Acta Biomaterialia, vol. 5, pp. 2322-2330.

[9] A New complex ceramic coating with carbon nanotubes, hydroxyapatite and $\mathrm{TiO} 2$ nanotubes on $\mathrm{Ti}$ surface for biomedical applications, Mariana Prodana, Marius Duta, Daniela Ionita, Dionezie Bojin, Miruna SStan, Anca Dinischiotu\&Ioana Demetrescu, 2015, Ceramics International, vol. 41, no. 5, pp. 6318-6325. 